Pacific Journal of Mathematics

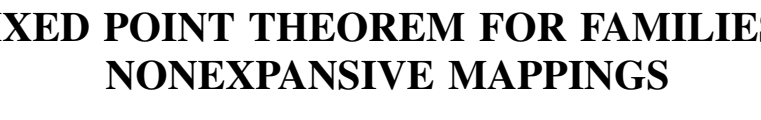




\title{
A FIXED POINT THEOREM FOR FAMILIES OF NONEXPANSIVE MAPPINGS
}

\author{
TECK-ChEONG LIM
}

\begin{abstract}
In this paper it is proved that if $K$ is a weakly compact convex subset of a Banach space and if $K$ has normal structure, then any family of commuting nonexpansive mappings on $K$ into itself admits a common fixed point.
\end{abstract}

Kirk [5] first proved that if $K$ is a nonempty weakly compact convex subset of a Banach space and if $K$ has normal structure [3], then every nonexpansive mapping $T: K \rightarrow K$ has a fixed point. Later, Belluce and Kirk [1] extend this theorem by showing that any finite family of commuting nonexpansive self-mappings of such a set $K$ always has a common fixed point. Their attempts to prove a common fixed point theorem for arbitrary families resulted in the need for a strengthening of normal structure called complete normal structure (see [2]). Since then the problem of whether their theorem is true for arbitrary families under the normal structure setting remained unsolved. In the present paper, we shall solve this problem by giving an affirmative answer. A technique used in the proof is the notion of asymptotic center which was first considered by Edelstein [4] to obtain a strong version of fixed point theorem in uniformly convex Banach spaces.

Throughout this paper, we shall denote the diameter of a set $A$ of $X$ by $\delta(A)$.

DEFINITION 1. Let $\left\{x_{\alpha}\right\}_{\alpha<r}$ be a bounded net, ordered by ordinals less than $\gamma$, in a convex set $C$ of a Banach space $X$, where $\gamma$ is an ordinal $\geqq 1$. For every $x \in C$ and every ordinal $\beta<\gamma$, define

$$
\begin{aligned}
r_{\beta}(x) & =\sup \left\{\left\|x-x_{\alpha}\right\|: \alpha \geqq \beta\right\} \\
r(x) & =\inf \left\{r_{\delta}(x): \delta<\gamma\right\}=\varlimsup \lim \left\|x-x_{\alpha}\right\|
\end{aligned}
$$

and

$$
r=\inf \{r(x): x \in C\} .
$$

The set $\{x \in C: r(x)=r\}$ (the number $r$ ) will be called the asymptotic center (asymptotic radius) of $\left\{x_{\alpha}\right\}_{\alpha<r}$ in $C$.

REMARK. Our main concern in this paper is the case where $\gamma=$ 认. for some $\delta \geqq 0$.

Some basic properties of $r(x)$ and asymptotic center: 
1. For each $x \in C,\left\{r_{\beta}(x)\right\}_{\beta<r}$ is a decreasing net with limit $r(x)$.

2. $r(x)=0$ if and only if $x_{\alpha} \rightarrow x$.

3. $|r(x)-r(y)| \leqq\|x-y\|$ for every $x, y \in C$. This follows from (1) and the fact that $\left|r_{\beta}(x)-r_{\beta}(y)\right| \leqq\|x-y\|$ for every $\beta<\gamma$.

4. $r(x)$ is a continuous convex function on $C$. This follows from (3), (1) and the fact that $r_{\beta}(x)$ are convex functions on $C$ for all $\beta<\gamma$.

5. $\{x \in C: r(x)=r\}$ is a closed convex subset of $C$. This follows from (4).

6. If $C$ is weakly compact convex, then $\{x \in C: r(x)=r\}$ is nonempty. This follows from (4), the equality $\{x \in C: r(x)=r\}=$ $\bigcap_{n=1}^{\infty}\{x \in C: r(x) \leqq r+1 / n\}$ and that closed convex subsets of weakly compact set are weakly compact.

Definition 2. A convex subset $C$ of a Banach space is said to have normal structure [3] if every bounded convex subset $D$ of $C$ with $|D|>1$ contains a point $x$ such that $\sup \{\|x-y\|: y \in D\}<\delta(D)$. A convex subset $C$ of a Banach space is said to have $\boldsymbol{\aleph}_{0}$-normal structure, $\delta \geqq 0$, if for every nonconstant bounded net $\left\{x_{\alpha}\right\}_{\alpha<\boldsymbol{N}_{\delta}}$ in $C$, the asymptotic center of $\left\{x_{\alpha}\right\}_{\alpha<\boldsymbol{N}_{\delta}}$ in $\mathrm{Co}\left(x_{\alpha}\right)_{\alpha<\boldsymbol{N}_{\delta}}$ is a proper subset of Co $\left(x_{\alpha}\right)_{\alpha<\boldsymbol{N}_{\delta}}$; in case that $C$ has $\boldsymbol{\aleph}_{\delta}$-normal structure for every $\delta \geqq 0$, we say that $C$ has asymptotic normal structure.

In their original paper [3], Brodskii and Milman characterized normal structure as follows: A convex subset of a Banach space has normal structure if and only if it contains no diametral sequences. (A diametral sequence is a nonconstant bounded sequence $\left\{x_{n}\right\}_{n=1}^{\infty}$ such that $d\left(x_{n+1}, \mathrm{Co}\left(x_{1}, \cdots, x_{n}\right)\right) \rightarrow \delta\left(\left\{x_{n}\right\}_{n=1}^{\infty}\right)$.) The following lemma is a simple variation of the above characterization.

LEMMA 1. A convex subset $C$ of a Banach space has normal structure if and only if it does not contain a sequence $\left\{x_{n}\right\}$ such that for some $c>0,\left\|x_{n}-x_{m}\right\| \leqq c,\left\|x_{n+1}-\bar{x}_{n}\right\| \geqq c-1 / n^{2}$ for all $n \geqq 1$, $m \geqq 1$, where $\bar{x}_{n}=1 / n \sum_{i=1}^{n} x_{i}$.

Proof. If $C$ contains a bounded convex subset such that $|D|>$ 1 and $\sup \{\|x-y\|: y \in D\}=\delta(D)$ for every $x \in D$, then it is easy to choose, by induction, a nonconstant sequence $\left\{x_{n}\right\} \subseteq D$ satisfying the condition in the lemma with $c=\delta(D)$. On the other hand, assume that $\left\{x_{n}\right\} \subseteq C$ is a sequence satisfying the condition in the lemma. If $x \in \operatorname{Co}\left(x_{1}, \cdots, x_{n}\right)$, it is not difficult to show that $x=\lambda_{1} \bar{x}_{n}+\lambda_{2} x_{i_{2}}+$ $\cdots+\lambda_{n} x_{i_{n}}$ for some $i_{2}, \cdots, i_{n} \in\{1, \cdots, n\}$ and $\lambda_{i}, 1 \leqq i \leqq n$, with $\sum_{i=1}^{n} \lambda_{i}=1,0<\lambda_{1} \leqq n$, and $\lambda_{j} \leqq 0$ for $2 \leqq j \leqq n$. It follows that $c \geqq\left\|x_{n+1}-x\right\| \geqq c-1 / n$ for every $n \geqq 1$ and every $x \in \operatorname{Co}\left(x_{1}, \cdots, x_{n}\right)$. Hence $d\left(x_{n+1}\right.$, Co $\left.\left(x_{1}, \cdots, x_{n}\right)\right) \rightarrow c$ and $c$ is necessarily equal to $\delta\left(\left\{x_{n}\right\}\right)$. 
In what follows, we shall use $r_{\beta}(x), r(x)$ and $r$ as is defined in Definition 1 without referring to the original net $\left\{x_{\alpha}\right\}_{\alpha<r}$ if no ambiguity can arise.

Proposition 1. A convex subset $C$ of a Banach space has normal structure if and only if it has $\boldsymbol{\aleph}_{0}$-normal structure.

Proof. Suppose $C$ has $\boldsymbol{\aleph}_{0}$-normal structure and suppose on the contrary that it contains a diametral sequence $\left\{u_{i}\right\}_{i=1}^{\infty}$ with diameter $\delta$. For every $x \in \operatorname{Co}\left(u_{i}\right)_{i=1}^{\infty}$, there is an integer $N$ such that $x \in \operatorname{Co}\left(u_{1}, \cdots, u_{m}\right)$ for all $m \geqq N$. Since $d\left(u_{i+1}\right.$, Co $\left.\left(u_{1}, \cdots, u_{i}\right)\right) \rightarrow \delta$ as $i \rightarrow \infty$, we have $r(x)=\varlimsup_{i}\left\|u_{i}-x\right\|=\delta$ for every $x \in \operatorname{Co}\left(u_{i}\right)_{i=1}^{\infty}$. This implies that $r=\delta$ and the asymptotic center of $\left\{u_{i}\right\}_{i=1}^{\infty}$ in $\operatorname{Co}\left(u_{i}\right)_{i=1}^{\infty}$ in $\operatorname{Co}\left(u_{i}\right)_{i=1}^{\infty}$ itself-a contradiction. Hence $C$ has normal structure by BrodskiiMilman's characterization.

Suppose now that $C$ does not have $\aleph_{0}$-normal structure. Then there exists a nonconstant bounded sequence $\left\{u_{i}\right\}_{i=1}^{\infty}$ such that $r(x)=$ $r$ for every $x \in \operatorname{Co}\left(u_{i}\right)_{i=1}^{\infty}$. By the basic property (2) following Definition 1 , we have $r>0$. Denoto Co $\left(u_{i}\right)_{i=1}^{\infty}$ by $D$.

Let $x_{1}$ be an arbitrary point in $C$. Since $r\left(x_{1}\right)=r$, there exists $x_{2} \in\left\{u_{i}\right\}_{i=1}^{\infty}$ such that $\left\|x_{1}-x_{2}\right\| \geqq r-1$; move $x_{2}$ towards $x_{1}$ along the line segment joining $x_{1}$ and $x_{2}$ if necessary, we may assume that $\left\|x_{1}-x_{2}\right\| \leqq r$. Suppose now that $\left\{x_{1}, \cdots, x_{n}\right\} \subseteq D, n \geqq 2$, has been chosen such that

$$
\left\|x_{i}-x_{j}\right\| \leqq r \quad(1 \leqq i \leqq n, 1 \leqq j \leqq n)
$$

and

$$
\left\|x_{n}-\bar{x}_{n-1}\right\| \geqq r-\frac{1}{(n-1)^{2}}
$$

where $\bar{x}_{n-1}=\sum_{i=1}^{n-1} x_{i}$. We proceed to choose $x_{n+1} \in D$ as follows: Let $m$ be an integer such that

$$
r_{m}\left(x_{i}\right) \leqq r+\frac{1}{n^{2}(n+1)} \quad(1 \leqq i \leqq n)
$$

and

$$
r_{m}\left(\bar{x}_{n}\right) \leqq r+\frac{1}{n^{2}(n+1)}
$$

Choose $z_{0} \in\left\{u_{m}, u_{m+1}, \cdots\right\}$ so that

$$
r_{m}\left(\bar{x}_{n}\right)-\left\|z_{0}-\bar{x}_{n}\right\| \leqq \frac{1}{n^{2}(n+1)} .
$$


Since $\max \left(\left\|z_{0}-\bar{x}_{n}\right\|, r\right) \leqq r_{m}\left(\bar{x}_{n}\right)$, we have, from (3) and (4),

$$
||\left|z_{0}-\bar{x}_{n} \|-r\right| \leqq \frac{1}{n^{2}(n+1)} .
$$

Let $\left\{z_{1}, \cdots, z_{n}\right\}$ be defined recursively by the formulae

$$
z_{i}=t_{i} x_{i}+\left(1-t_{\imath}\right) z_{\imath-1} \quad(1 \leqq i \leqq n)
$$

where

$$
t_{\imath}=\max \left(\frac{\left\|x_{\imath}-z_{2-1}\right\|-r}{\left\|x_{i}-z_{i-1}\right\|}, 0\right)
$$

for each $1 \leqq i \leqq n$. We then define $x_{n+1}=z_{n}$.

Geometrically, $x_{n+1}$ is obtained by first moving $z_{0}$ along the line segment joining $x_{1}$ and $z_{0}$ so that its distance with $x_{1}$ becomes $r$ (keeping $z_{0}$ unmoved if its distance with $x_{1}$ is already not greater than $r$ ) and then moving the resulting point towards $x_{2}$ in the same manner and continuing so on, up to $n$ times.

It is geometrically clear and can be easily proved that $\left\|x_{n+1}-x_{i}\right\| \leqq$ $r$ for all $1 \leqq i \leqq n$. By making use of (1), (2), (6) and the fact that $z_{0} \in\left\{u_{m}, u_{m+1}, \cdots\right\}$, one can easily show that

$$
\left\|x_{i}-z_{\imath-1}\right\| \leqq r+\frac{1}{n^{2}(n+1)}
$$

for all $1 \leqq i \leqq n$. Since

$$
\left\|z_{i}-z_{\imath-1}\right\|=t_{\imath}\left\|x_{\imath}-z_{\imath-1}\right\| \leqq \max \left(\left\|x_{\imath}-z_{\imath-1}\right\|-r, 0\right)
$$

by (6), we have, by (7),

$$
\left\|x_{n+1}-z_{0}\right\| \leqq\left\|z_{0}-z_{1}\right\|+\cdots+\left\|z_{n-1}-z_{n}\right\| \leqq \frac{n}{n^{2}(n+1)}
$$

and therefore

$$
\left\|x_{n+1}-\bar{x}_{n}\right\| \geqq\left\|z_{0}-\bar{x}_{n}\right\|-\left\|x_{n+1}-z_{0}\right\| \geqq r-\frac{1}{n^{2}}
$$

by (5). Clearly, $x_{n+1} \in D$. Thus, by induction, we have constructed a sequence $\left\{x_{n}\right\}$ satisfying the condition in Lemma 1 with $c=r>0$. This implies that $C$ has no normal structure and the proof is complete.

Proposition 2. A convex subset $C$ of a Banach space has normal structure if and only if it has asymptotic normal structure.

Proof. The sufficiency part follows from Proposition 1. For 
necessity, suppose that $C$ has normal structure. Suppose on the contrary that $C$ does not have $\aleph_{\lambda}$-normal structure for some $\lambda \geqq 0$. By Proposition 1 , we must have $\lambda \geqq 1$. Then there exists a nonconstant bounded net $\left\{x_{\alpha}\right\}_{\alpha<\boldsymbol{N}_{\lambda}}$ in $C$ such that $r(x)=r$ for all $x \in \mathrm{Co}\left(x_{\alpha}\right)_{\alpha<\boldsymbol{N}_{\lambda}}$,

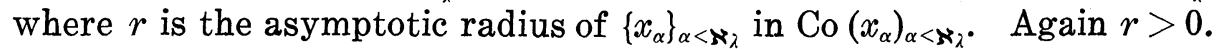

For each $x \in \mathrm{Co}\left(x_{\alpha}\right)_{\alpha<\boldsymbol{N}_{\lambda}}$, we associate with it an ordinal $\beta(x)<\boldsymbol{\aleph}_{2}$ as follows: Since $r(x)=r,\left\{\sup _{\alpha \geqq \beta}\left\|x-x_{\alpha}\right\|: \beta<\boldsymbol{\aleph}_{\lambda}\right\}$ is a decreasing net in $R$ with infimum $r$ so that there exists an increasing sequence $\left\{\beta_{i}\right\}_{i=1}^{\infty}$ of ordinals less than $\boldsymbol{\aleph}_{i}$ with $\lim _{i} \sup _{\alpha \geq \beta_{i}}\left\|x-x_{\alpha}\right\|=r$. We then put $\beta(x)=\sup \left\{\beta_{i}: i \geqq 1\right\}$. Since $\lambda \geqq 1, \beta(x)<\boldsymbol{\aleph}_{i}$.

It follows from the definition of $\beta(x)$ that $\sup \left\{\left\|x-x_{\alpha}\right\|: \alpha \geqq \gamma\right\}=$ $r$ for every $\gamma \geqq \beta(x)$. This implies that for every $\varepsilon>0$, for every $\gamma \geqq \beta(x)$, there exists an ordinal $\alpha>\gamma$ such that $r \geqq\left\|x_{\alpha}-x\right\| \geqq r-\varepsilon$.

Let $u_{1}=x_{0}$. Choose $\alpha>\beta\left(u_{1}\right)$ such that $r \geqq\left\|x_{\alpha}-u_{1}\right\| \geqq r-1$ and put $u_{2}=x_{\alpha}$. Suppose that $u_{1}, \cdots, u_{n}, n \geqq 2$, have been chosen such that $u_{i} \in\left\{x_{\alpha}\right\}_{\alpha<\boldsymbol{N}_{\lambda}}, \quad\left\|u_{i}-u_{j}\right\| \leqq r \quad(1 \leqq i \leqq n, 1 \leqq j \leqq n)$ and $\left\|u_{n}-\bar{u}_{n-1}\right\| \geqq r-1 /(n-1)^{2}$, where $\bar{u}_{n-1}=\sum_{i=1}^{n-1} u_{i}$. Let $p=$ $\max \left(\beta\left(u_{1}\right), \cdots, \beta\left(u_{n}\right), \beta\left(\bar{u}_{n}\right)\right)$, where $\bar{u}_{n}=\sum_{i=1}^{n} u_{i}$. Choose $u_{n+1} \in\left\{x_{\alpha}\right\}_{p<\alpha<\boldsymbol{N}_{\lambda}}$ such that $\left\|u_{n+1}-\bar{u}_{n}\right\| \geqq r-1 / n^{2}$; this is possible since $p \geqq \beta\left(\bar{u}_{n}\right)$. That $\left\|u_{n+1}-u_{i}\right\| \leqq r$ for every $1 \leqq i \leqq n$ is also true since $p \geqq \beta\left(u_{i}\right)$ for each $i=1, \cdots, n$. Hence, by induction, we have constructed a sequence $\left\{u_{i}\right\}_{i=1}^{\infty} \subseteq\left\{x_{\alpha}\right\}_{\alpha<\boldsymbol{N}_{\lambda}}$ such that the condition in Lemma 1 is satisfied with $c=r$. This is a contradiction to the assumption that $C$ has normal structure by Lemma 1 and the proof is complete.

REMARK. One can also define $\gamma$-normal structure for ordinals $\gamma \geqq 1$ and prove that a convex set has normal structure if and only if it has $\gamma$-normal structure for all ordinals $\gamma \geqq 1$.

We are now in the position of proving the following theorem:

THEOREM 1. Let $K$ be a nonempty weakly compact convex subset of a Banach space and assume that $K$ has normal structure. Let $\mathscr{F}$ be an arbitrary family of commuting nonexpansive maps from $K$ into itself. Then $\mathscr{F}$ has a common fixed point.

Proof. The theorem is true for $|\mathscr{F}|<\boldsymbol{\aleph}_{0}$ by Belluce-Kirk's theorem [1], so we assume that $\mathscr{F}$ is infinite. We shall first prove the theorem for $|\mathscr{F}|=\boldsymbol{\aleph}_{0}$ and assume that it is true for $|\mathscr{F}|=\boldsymbol{\aleph}_{\alpha}$ for every $\alpha<\gamma$, then prove it for the case $|\mathscr{F}|=\boldsymbol{\aleph}_{r}$. This would complete the proof by transfinite induction.

Suppose that $|\mathscr{F}|=\boldsymbol{\aleph}_{0}$ and let $\mathscr{F}=\left\{f_{1}, f_{2}, \cdots\right\}$. Since closed convex subsets of $K$ are weakly compact, we can apply Zorn's lemma to obtain a subset $M$ of $K$ which is minimal with respect to being 
nonempty, closed, convex and mapped into itself by every member of $\mathscr{F}$. Suppose $M$ is not a singleton. For each $n$, let $x_{n}$ be a common fixed point in $M$ of $\left\{f_{1}, \cdots, f_{n}\right\}$; this is possible by [1]. Since $M$ is minimal, $\left\{x_{i}\right\}_{i=1}^{\infty}$ is not a constant sequence. Let $B$ be the asymptotic center of $\left\{x_{i}\right\}_{i=1}^{\infty}$ in $M$. By weakly compactness of $M, B \neq \varnothing$. If $B=M$, then $r(x)=r(y)$ for every $x, y$ in $M$, in particular $r(x)=$ $r(y)$ for every $x, y \in \operatorname{Co}\left(X_{i}\right)_{i=1}^{\infty}$. This implies that the asymptotic center of $\left\{x_{i}\right\}_{i=1}^{\infty}$ in $\mathrm{Co}\left(x_{i}\right)_{i=1}^{\infty}$ is Co $\left(x_{i}\right)_{i=1}^{\infty}$ itself-a contradiction to normal structure of $K$ by Proposition 1 . Hence $B$ is a proper (closed convex nonempty) subset of $M$. For every $x \in B$, every $f_{n} \in \mathscr{F}$, we have $\left\|x_{m}-f_{n}(x)\right\|=\left\|f_{n}\left(x_{m}\right)-f_{n}(x)\right\| \leqq\left\|x_{m}-x\right\|$ for every $m \geqq n$ so that $r\left(f_{n}(x)\right)=\varlimsup_{\lim _{m}}\left\|x_{m}-f_{n}(x)\right\| \leqq \varlimsup_{\lim _{m}}\left\|x_{m}-x\right\|=r(x)=r$, and therefore $f_{n}(x) \in B$. This shows that $B$ is also mapped into itself by every member of $\mathscr{F}$-a contradiction to the minimality of $M$. Hence $M$ consists of a single point which must be a common fixed point of $\mathscr{F}$.

Suppose that the theorem is true for all such families $\mathscr{F}$ with $|\mathscr{F}|=\aleph_{\alpha}$ for some $\alpha<\gamma$. Let $\mathscr{F}$ be a family satisfying the condition in the theorem and $|\mathscr{F}|=\boldsymbol{\aleph}_{r}$. By previous reasoning, $K$ contains a subset $M$ which is minimal with respect to being nonempty, closed, convex and mapped into itself by each member of $\mathscr{F}$. If $M$ is not a singleton, define a net $\left\{x_{\alpha}\right\}_{\alpha<\boldsymbol{N}_{i}}$ as follows: For each $\alpha<\boldsymbol{\aleph}_{r}$, either $\left|\left\{f_{\alpha}\right\}_{\beta \leqq \alpha}\right|=\boldsymbol{\aleph}_{\alpha_{0}}$ for some $\alpha_{0}<\gamma$ or $\left|\left\{f_{\beta}\right\}_{\beta \leqq \alpha}\right|<\boldsymbol{\aleph}_{0}$, so that by induction hypothesis or Belluce-Kirk's theorem, $\left\{f_{\beta}\right\}_{\beta \leqq \alpha}$ has a common fixed point which we call $x_{\alpha}$. An argument parallel to the previous one together with Proposition 2 shows that the asymptotic center of $\left\{x_{\alpha}\right\}_{\alpha<\aleph_{\lambda}}$ in $M$ is a proper subset of $M$ and is closed, convex, nonempty and mapped into itself by each member of $\mathscr{F}$. This is a contradiction. Hence $M$ consists of a single point which is a common fixed point of $\mathscr{F}$, completing the proof.

The special feature of the above proof leads to the following

Theorem 2. Let $K$ be defined as in Theorem 1. Let $\mathscr{F}$ be a family of nonexpansive self-mappings of $K$ such that every finite subfamily of $\mathscr{F}$ has a common fixed point in every $\mathscr{F}$-invariant closed convex nonempty subset of $K$. Then $\mathscr{F}$ has a common fixed point.

REMARK. The technique of asymptotic center can also be applied to prove, by induction, Theorem 1 for finite families through the following facts which had been implicitly used in [4] in the case of uniformly convex Banach spaces.

1. If $f$ is a nonexpansive mapping on a bounded convex set $C$ into itself and $x \in C$, then the asymptotic center of $\left\{x, f(x), f^{2}(x), \cdots\right\}$ in $C$ is mapped into itself by $f$.

2. If $f_{1}, \cdots, f_{n}$ are commuting nonexpansive mappings on a 
bounded convex set $C$ into itself, and $x$ is a common fixed point of $f_{1}, \cdots, f_{n-1}$, then the asymptotic center of $\left\{x, f_{n}(x), f_{n}^{2}(x), \cdots\right\}$ in $C$ is mapped into itself by each $f_{i}, 1 \leqq i \leqq n$.

\section{REFERENCES}

1. L. P. Belluce and W. A. Kirk, Fixed point theorems for families of contraction mappings, Pacific J. Math., 18 (1966), 213-217.

2. — Nonexpansive mappings and fixed-points in Banach spaces, Illinois J. Math., 11 (1967), 474-479.

3. M. S. Brodskii and D. P. Milman, On the center of a convex set, Dokl. Akad. Nauk SSSR (N.S.), 59 (1948), 837-840.

4. M. Edelstein, Fixed point theorems in uniformly convex Banach spaces, Proc. Amer. Math. Soc., 44 (1974), 369-374.

5. W. A. Kirk, A fixed point theorem for mappings which do not increase distances, Amer. Math. Monthly, 72 (1965), 1004-1006.

Received May 31, 1973.

DALHOUSIE UNIVERSITY

Present address: The University of Chicago 



\section{PACIFIC JOURNAL OF MATHEMATICS}

\section{EDITORS}

RICHARD ARENS (Managing Editor)

University of California

Los Angeles, California 90024

\section{J. DUGUNDJI}

Department of Mathematics University of Southern California Los Angeles, California 90007

D. Gilbarg and J. Milgram

Stanford University

Stanford, California 94305

University of Washington
Seattle, Washington 98105

ASSOCIATE EDITORS
E. F, BECKENBACH
B. H. NEUMANN
F. WOLF
K. Yoshida

\section{SUPPORTING INSTITUTIONS}

\author{
UNIVERSITY OF BRITISH COLUMBIA \\ CALIFORNIA INSTITUTE OF TECHNOLOGY \\ UNIVERSITY OF CALIFORNIA \\ MONTANA STATE UNIVERSITY \\ UNIVERSITY OF NEVADA \\ NEW MEXICO STATE UNIVERSITY \\ OREGON STATE UNIVERSITY \\ UNIVERSITY OF OREGON \\ OSAKA UNIVERSITY
}

\author{
UNIVERSITY OF SOUTHERN CALIFORNIA \\ STANFORD UNIVERSITY \\ UNIVERSITY OF TOKYO \\ UNIVERSITY OF UTAH \\ WASHINGTON STATE UNIVERSITY \\ UNIVERSITY OF WASHINGTON \\ * * * * \\ AMERICAN MATHEMATICAL SOCIETY \\ NAVAL WEAPONS CENTER
}

The Supporting Institutions listed above contribute to the cost of publication of this Journal, but they are not owners or publishers and have no responsibility for its content or policies.

Mathematical papers intended for publication in the Pacific Journal of Mathematics should be in typed form or offset-reproduced, (not dittoed), double spaced with large margins. Underline Greek letters in red, German in green, and script in blue. The first paragraph or two must be capable of being used separately as a synopsis of the entire paper. Items of the bibliography should not be cited there unless absolutely necessary, in which case they must be identified by author and Journal, rather than by item number. Manuscripts, in duplicate if possible, may be sent to any one of the four editors. Please classify according to the scheme of Math. Rev. Index to Vol. 39. All other communications to the editors should be addressed to the managing editor, or Elaine Barth, University of California, Los Angeles, California, 90024.

100 reprints are provided free for each article, only if page charges have been substantially paid. Additional copies may be obtained at cost in multiples of 50 .

The Pacific of Journal Mathematics is issued monthly as of January 1966. Regular subscription rate: $\$ 72.00$ a year (6 Vols., 12 issues). Special rate: $\$ 36.00$ a year to individual members of supporting institutions.

Subscriptions, orders for back numbers, and changes of address should be sent to Pacific Journal of Mathematics, 103 Highland Boulevard, Berkeley, California, 94708.

PUBLISHED BY PACIFIC JOURNAL OF MATHEMATICS, A NON-PROFIT CORPORATION

Printed at Kokusai Bunken Insatsusha (International Academic Printing Co., Ltd.), 270, 3-chome Totsuka-cho, Shinjuku-ku, Tokyo 160, Japan.

Copyright (C) 1973 by Pacific Journal of Mathematics Manufactured and first issued in Japan 


\section{Pacific Journal of Mathematics}

\section{Vol. 53, No. $2 \quad$ April, 1974}

Kenneth Abernethy, On characterizing certain classses of first countable spaces by

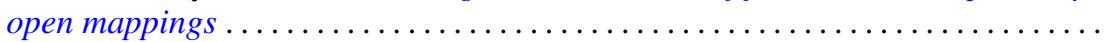

Ross A. Beaumont and Donald Lawver, Strongly semisimple abelian groups .......

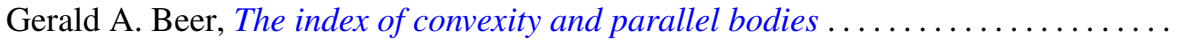

Victor P. Camillo and Kent Ralph Fuller, On Loewy length of rings ..............

Stephen LaVern Campbell, Linear operators for which $T^{*} T$ and $T T^{*}$ commute.

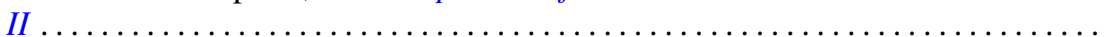

Charles Kam-Tai Chui and Philip Wesley Smith, Characterization of a function by

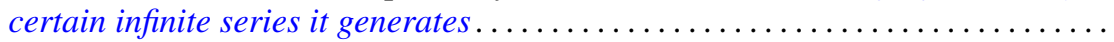

Allan L. Edelson, Conjugations on stably almost complex manifolds . ...........

Patrick John Fleury, Hollow modules and local endomorphism rings . . ..........

Jack Tilden Goodykoontz, Jr., Connectedness im kleinen and local connectedness in

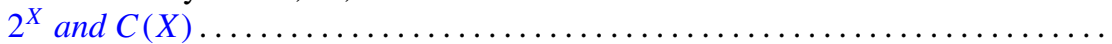

Robert Edward Jamison, II, Functional representation of algebraic intervals .......

Athanassios G. Kartsatos, Nonzero solutions to boundary value problems for

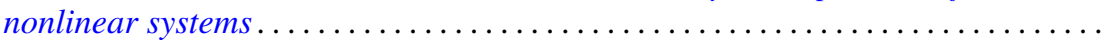

Soon-Kyu Kim, Dennis McGavran and Jingyal Pak, Torus group actions on simply

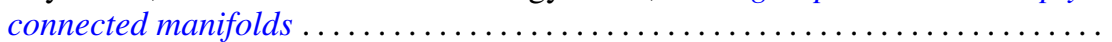

David Anthony Klarner and R. Rado, Arithmetic properties of certain recursively

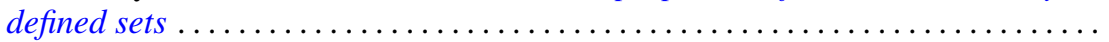

Ray Alden Kunze, On the Frobenius reciprocity theorem for square-integrable

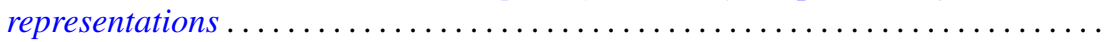

John Lagnese, Existence, uniqueness and limiting behavior of solutions of a class of differential equations in Banach space...

Teck Cheong Lim, A fixed point theorem for families on nonexpansive mappings Lewis Lum, A quasi order characterization of smooth continua

Andy R. Magid, Principal homogeneous spaces and Galois extensions . .

Charles Alan McCarthy, The norm of a certain derivation ..... . .

Louise Elizabeth Moser, On the impossibility of obtaining $S^{2} \times S^{1}$ by elementary surgery along a knot. .

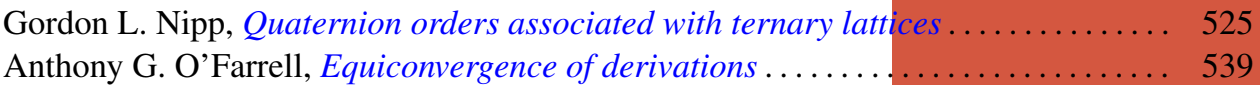

Dorte Olesen, Derivations of $A W^{*}$-algebras are inner . . . . . . . . . . . . . . . 555

Dorte Olesen and Gert Kjærgaard Pedersen, Derivations of $C^{*}$-algebras have

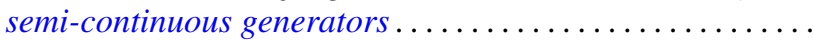

Duane O’Neill, On conjugation cobordism.

Chull Park and S. R. Paranjape, Probabilities of Wiener paths crossing differentiable

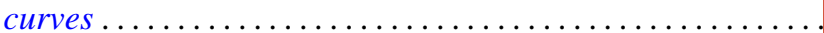

Edward Ralph Rozema, Almost Chebyshev subspaces of $L^{1}(\mu$;

Lesley Millman Sibner and Robert Jules Sibner, A note on the Atiyah-Bott fixed

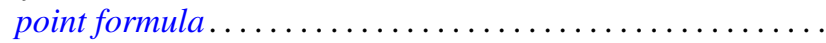

Betty Salzberg Stark, Irreducible subgroups of orthogonal groups generated by

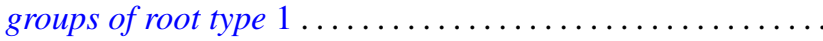

N. Stavrakas, A note on starshaped sets, $(k)$-extreme points and the half ray

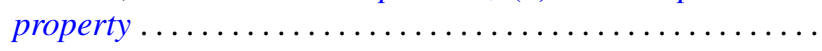

Carl E. Swenson, Direct sum subset decompositions of $Z \ldots \ldots$ 